\title{
SISTEM REPOSITORY PERPUSTAKAAN DI UNIVERSITAS BANTEN JAYA BERBASIS WEB (STUDI KASUS : UNIVERSITAS BANTEN JAYA)
}

\author{
Raden Kania ${ }^{2}$, Rustam Effendi ${ }^{3}$, Muh. Rizal Sidik ${ }^{1}$ \\ ${ }^{1,2,3}$ UNIVERSITAS BANTEN JAYA \\ Jl.Ciwaru II No. 73 Kota Serang Banten \\ Email : kania@unbaja.ac.id ${ }^{3}$, rustameffendi@unbaja.ac.id ${ }^{2}$, \\ muhrizalsidik@gmail.com ${ }^{3}$
}

\begin{abstract}
The library repository system located at Banten Jaya University is not currently utilizing information technology to the maximum. This is seen from the library member registration information system and the ongoing report data storage system, the system is still manually done by filling out the form on paper and also still the manual storage of scientific work report data, if it has finished filling out the form the library must re-input on the application. In this way it is certainly less effective and efficient. Based on the results of the system research that the authors conducted, with the update of the repository system this web-based library can provide ease to the officer in managing the library information system. The research method used is waterfall development model, which consists of analysis, design, implementation, and testing. The development of this web-based library information system uses php7 language for system functionality because it is very effective for building web-based applications. The result of this study is the development of repository applications that can facilitate students in accessing scientific work in the Library of Banten Jaya University. Using the Repository application can reduce damage, lose scientific work collections, make it easier to use libraries and save space usage and by implementing repository applications are expected to support library performance and assist library users in finding the information they need.
\end{abstract}

Keywords:System, Repositories, Waterfall, Web.

\section{PENDAHULUAN}

Perpustakaan perguruan yinggi adalah bagian integral dari pendidikan, penelitian dan pengabdian kepada masyarakat dan berfungsi sebagai pusat sumber belajar untuk mendukung tercapainya tujuan pendidikan yang berkedudukan di perguruan tinggi(Perpustakaan Nasional Republik Indonesia, 2015). Tujuan penyelenggaraan perpustakaan perguruan tinggi yang merupakan bagian integral dari suatu perguruan tinggi adalah untuk menunjang pelaksanaan program perguruan tinggi, sesuai dengan tri dharma perguruan tinggi yaitu: pendidikan dan pengajaran, penelitian, serta pengabdian pada masyarakat dengan menyediakan 
bahan perpustakaan dan akses informasi bagi pemustaka, meningkatkan literasi informasi pemustaka dan mendayagunakan teknologi informasi dan komunikasi serta melestarikan bahan perpustakaan, baik isi maupun medianya. Perpustakaan perguruan tinggi juga dituntut untuk dapat sensntiasa mampu memanfaatkan teknologi yang semakin pesat berkembang sehingga keberadaannya dapat dimanfaatkan secara optimal.

Pandemi Covid-19 yang berlangsung dari awal tahun 2019 sampai saat ini membatasi pelayanan perpustakaan kepada penggunanya. Pembatasan Sosial Berskala Besar menyebabkan mahasiswa tidak dapat lagi leluasa mengakses koleksi perpustakaan, untuk memutus mata rantai penyebaran covid-19 di semua lini termasuk di Lembaga Pendidikan, sehingga sekolah-sekolah ditutup untuk sementara waktu. Hal ini mendorong pustakawan untuk dapat senantiasa memberikan layanan, baik secara offline maupun online.

Perpustakaan UNBAJA yang terletak di Jl. Ciwaru Raya No.73 Kota Serang (Kampus 1 UNBAJA) di ruang khusus yang disebut dengan Ruang Koleksi Referensi. Perpustakaan Universitas Banten Jaya (UNBAJA) melayani empat Fakultas (Fakultas Ilmu Komputer (lima prodi), Fakultas Teknik(tiga prodi), Fakultas Keguruan dan Ilmu Pendidikan(tiga prodi) serta Fakultas Ekonomi dan Bisnis(tiga prodi)). Perpustakaan Universitas Banten Jaya menghimpun berbagai koleksi karya ilmiah mahasiswa dan dosen (berupa Laporan Praktek Kerja Nyata, Proposal Mahasiswa FKIP, Laporan Kuliah Praktek, Skripsi, Tugas Akhir, hasil penelitian dosen dan mahasiswa serta berbagai koleksi jurnal ilmiah, prosiding nasional dan internasional yang jumlahnya cukup banyak), sehingga perlu disiangi/weeding dalam jangka waktu tertentu. Koleksi yang semakin bertambah mendorong perpustakaan untuk mengalihmediakan koleksi karya ilmiahnya ke dalam bentuk digital dengan harapan agar ruangan menjadi lebih lapang dan koleksi dapat diakses di mana saja. Selama ini pengguna dapat menggunakan koleksi tersebut pada Setiap tahun koleksi referensi semakin bertambah, sehingga ruangan yang ada tidak lagi mampu menampung karya ilmiah tersebut. Sistem repository perpustakaan yang terdapat pada Universitas Banten Jaya saat ini belum memanfaatkan teknologi informasi dengan maksimal. Hal ini terlihat dari Sistem informasi pendaftaran anggota perpustakaan dan penyimpanan data laporan yang sedang berjalan, sistem tersebut masih manual dilakukan dengan pengisian formulir pada kertas dan juga masih manualnya penyimpanan data laporan karya ilmiah, jika sudah selesai pengisian formulir pihak perpustakaan harus menginput ulang pada aplikasi sehingga membutuhkan waktu yang lebih lama dan tenaga yang lebih banyak, karena karya mahasiswa dan dosen demikian banyak. 
Pembaruan sistem repository perpustakaan(Rodliyah \& Habib, 2019) berbasis web dapat memberikan kemudahan kepada petugas dalam mengelola sistem informasi perpustakaan.

(Sommerville, 2011) Metode pengembangan Sistem Informasi menggunakan Waterfall Model yang dimulai dengan (K. Kania et al., 2019)analisis, desain, pengkodean dan pengujian (R. Kania, Effendy, et al., 2021). Pengembangan sistem (system development) (K. Kania et al., 2019)dapat berarti menyusun suatu sistem yang baru untuk menggantikan sistem yang lama secara keseluruhan atau memperbaiki sistem yang telah ada (Hasugian, 2011)

Menurut Random House Dictionary of the English Language dalam (Saleh \& Komalasari, 2014) Perpustakaan adalah suatu tempat, berupa sebuah ruangan atau gedung yang berisi buku-buku dan bahan-bahan lain untuk bacaan, studi maupun rujukan(Pendit, 2013). Definisi sistem adalah suatu jaringan prosedur yang dibuat menurut pola yang terpadu untuk melaksanakan kegiatan pokok perusahaan. (R. Kania, Hidayanti, et al., 2021) mengungkapkan bahwa website adalah kumpulan dari berbagai macam halaman situs, yang terangkum didalam sebuah domain atau juga subdomain, yang lebih tempatnya berada di dalam WWW (World Wide Web) yang tentunya terdapat di dalam internet.

Sistem berasal dari bahasa (R. Kania, Effendy, et al., 2021)Latin systēma dan bahasa Yunani sustēma adalah sekumpulan unsur atau elemen yang saling berkaitan dan(Tiningsih, 2011) saling mempengaruhi dalam melakukan kegiatan bersama untuk mencapai suatu tujuan. Sistem merupakan sebuah objek yang dikaji atau dipelajari yang memiliki karakteristik tertentu atau spesifikasi tersendiri(Cahyono, 2015). Perpustakaan perguruan tinggi memiliki fungsi edukatif, informasi, riset, rekreasi, publikasi, deposit dan interpretasi(Untuk et al., 2014). Secara tidak langsung perpustakaan perguruan tinggi berfungsi untuk menunjang tri dharma perguruan tinggi yaitu Pendidikan, penelitian dan pengabdian kepada masyarakat sehingga keberadaannya sangat dibutuhkan bagi seluruh sivitas akademika(Sri, 2012).

Kebijakan manajemen pendidikan di Indonesia saat ini mendorong seluruh level pendidikan, terutama pendidikan tinggi untuk memanfaatkan kemajuan teknologi digital dan komputasi pendidikan era revolusi industry keempat(Reflianto \& Syamsuar, 2018). Demukian pun dengan perpustakaan, harus mampu mengadopsi perkembangan teknologi dalam upaya memberikan pelayanan terbaik bagi para penggunanya(Pendit, 2013). Repository perpustakaan yang sebelumnya berbasis pelayanan konvensional melalui media cetak baik berupa book materials (skripsi, prosiding, jurnal) maupun dalam bentuk compact disk, dan soft file yang tersimpan pada komputer perpustakaan yang hanya dapat diakses saat berada di perpustakaan, menjadi materi digital yang mudah diakses di mana pun dan kapan pun dibutuhkan oleh penggunanya (berbasis online)(Siregar, 2013).

Masalah yang dihadapi yaitu proses penginputan data masih dilakukan secara konvensional, laporan pengguna dan data koleksi repository lambat dilakukan, dan system repository yang ada harus diakses secara langsung. Sistem Repository yang dibuat diharapkan mampu untuk mengolah data anggota, untuk memudahkan pekerjaan pustakawan, meningkatkan pelayanan secara online 
kepada mahasiswa di Universitas Banten Jaya dan untuk mempermudah proses pengolahan data laporan karya ilmiah pada perpustakaan Universitas Banten Jaya. Sistem repository perpustakaan pernah dilakukan namun ada beberapa kekurangan diantaranya adalah belum adanya menu untuk upload dokumen oleh mahasiswa/anggota perpustakaan dan verifikasi dari pustakwan(Ruhiawati et al., 2020)

Sistem repository perpustakaan pada Universitas Banten Jaya, saat ini belum diaplikasikan di perpustakaan Universitas Banten Jaya sehingga informasi mengenai karya ilmiah mengalami kesulitan diperoleh mahasiswa dan dosen. Penelitian ini diharapkan akan dapat membantu mengolah data karya ilmiah seperti, cari referensi judul karya ilmiah yang sudah tersedia, dan jurnal serta membuat laporan-laporan kebutuhan sistem perpustakaan terutama laporan karya ilmiah yang lebih cepat untuk kebutuhan penilaian kinerka perpustakaan.

Pengembangan sistem informasi perpustakaan berbasis web ini menggunakan bahasa PHP7 untuk fungsi sistem karena sangat efektif untuk membangun aplikasi berbasis web(Tarigan \& Ardiansyah, 2020). Penelitian ini adalah berupa pengembangan aplikasi repository(Siregar, 2013) yang dapat memudahkan mahasiswa dalam mengakses karya ilmiah pada Perpustakaan Universitas Banten Jaya. Dengan menggunakan aplikasi Repository dapat mengurangi terjadinya kerusakan, kehilangan koleksi karya ilmiah, mempermudah penggunaan perpustakaan dan menghemat penggunaan ruangan dan dengan diterapkan aplikasi Repository diharapkan dapat menunjang kinerja perpustakaan dan membantu para pengguna perpustakaan dalam mencari informasi yang dibutuhkan. 


\section{METODE}

Metode yang digunakan dalam pengembangan system repository perpustakaan adalah Waterfall Model, yang secara sederhana dapat dilaksanakan dengan kegiatan-kegiatan sebagai berikut; analisa, desain, implementasi(Ruhiawati et al., 2020)

Waterfall model is a software process model that involves discrete development stage: specification, design, implementation, testing and maintenance. In principle, one stage must be complete before progress to the next stage is possible. In practice, there is significant itteration between stages(Sommerville, 2011)

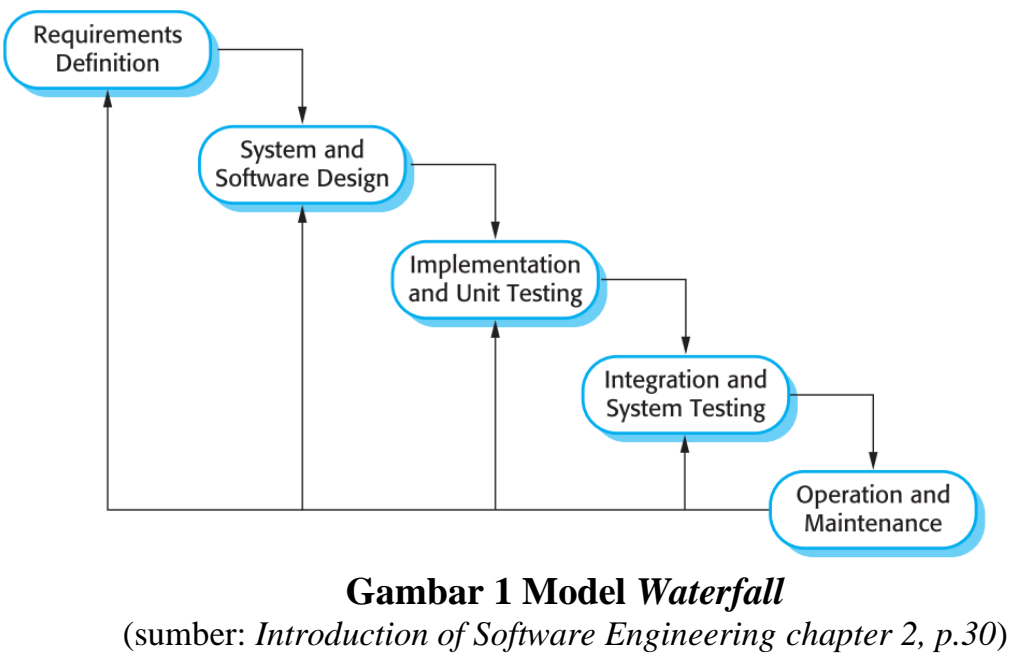

Dalam melakukan penelitian menggunakan beberapa metode pengumpulan data yang akurat, antara lain :

1. Observasi

Melakukan pengamatan langsung pada objek untuk mendapatkan data yang tepat serta mengetahui gambaran secara jelas dan lengkap terhadap permasalahan yang terjadi di lapangan.

2. Wawancara

Wawancara adalah suatu cara untuk mengumpulkan data dengan mengajukan pertanyaan langsung kepada narasumber.

3. Studi Pustaka

Pencarian data dengan membaca dan mempelajari melalui media buku dan sumber lainnya yang berkaitan dengan tugas akhir.

\section{PEMBAHASAN}

Setelah melakukan observasi, interview maka peneliti menyimpulkan bahwa sistem yang sedang berjalan sehingga terbentuknya keluaran yang dibutuhkan dapat digambarkan dalam overview diagram, sebagai berikut : 


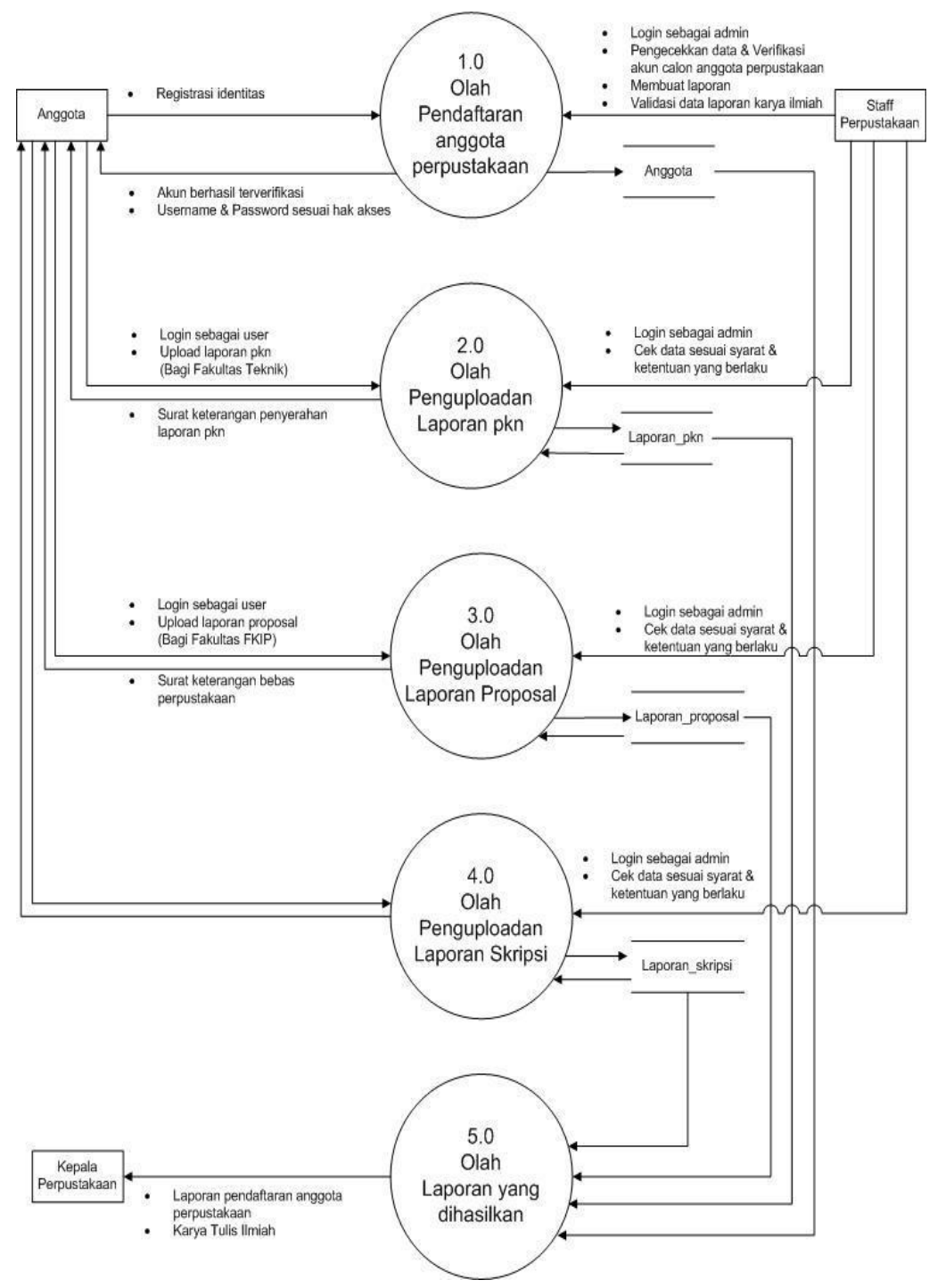

Gambar 2. Diagram Overview Sistem Berjalan

Penjelasan :

1. User / calon anggota membuat akun terlebih dahulu, dengan mendaftarkan identitas terlebih dahulu pada form registrasi repository Universitas Banten Jaya.

2. Admin mengecek identitas calon anggota kemudian memverifikasi akun anggota.

3. Akun anggota yang sudah terverifikasi dapat login dengan username dan password yang telah terdaftar di website Repository Universitas Banten Jaya.

4. Anggota dapat dengan mudah mengunggah hasil laporan PKN, Proposal, maupun laporan Skripsi di web Repository Universitas Banten Jaya.

5. Admin mengecek hasil laporan yang telah di upload oleh anggota perpustakaan dan memvalidasinya jika sudah sesuai ketentuan yang berlaku. 
6. Setelah proses validasi dan penyerahan laporan selesai dilakukan maka pihak admin mencetak surat penyerahan laporan PKN, Proposal, maupun Skripsi dan ditandatangani oleh kepala perpustakaan, kemudian diserahkan kepada anggota perpustakaan yang telah menyerahkan hasil laporannya.

7. Peneliti selain membuat diagram overview proses repository maka mengumpulkan dokumen-dokumen yang bertujuan untuk mengetahui dan memberikan informasi sebagai masukan pada saat perancangan perangkat lunak yang diusulkan.

8. Sumber dokumen untuk perdaftaran anggota baru, seperti berikut :

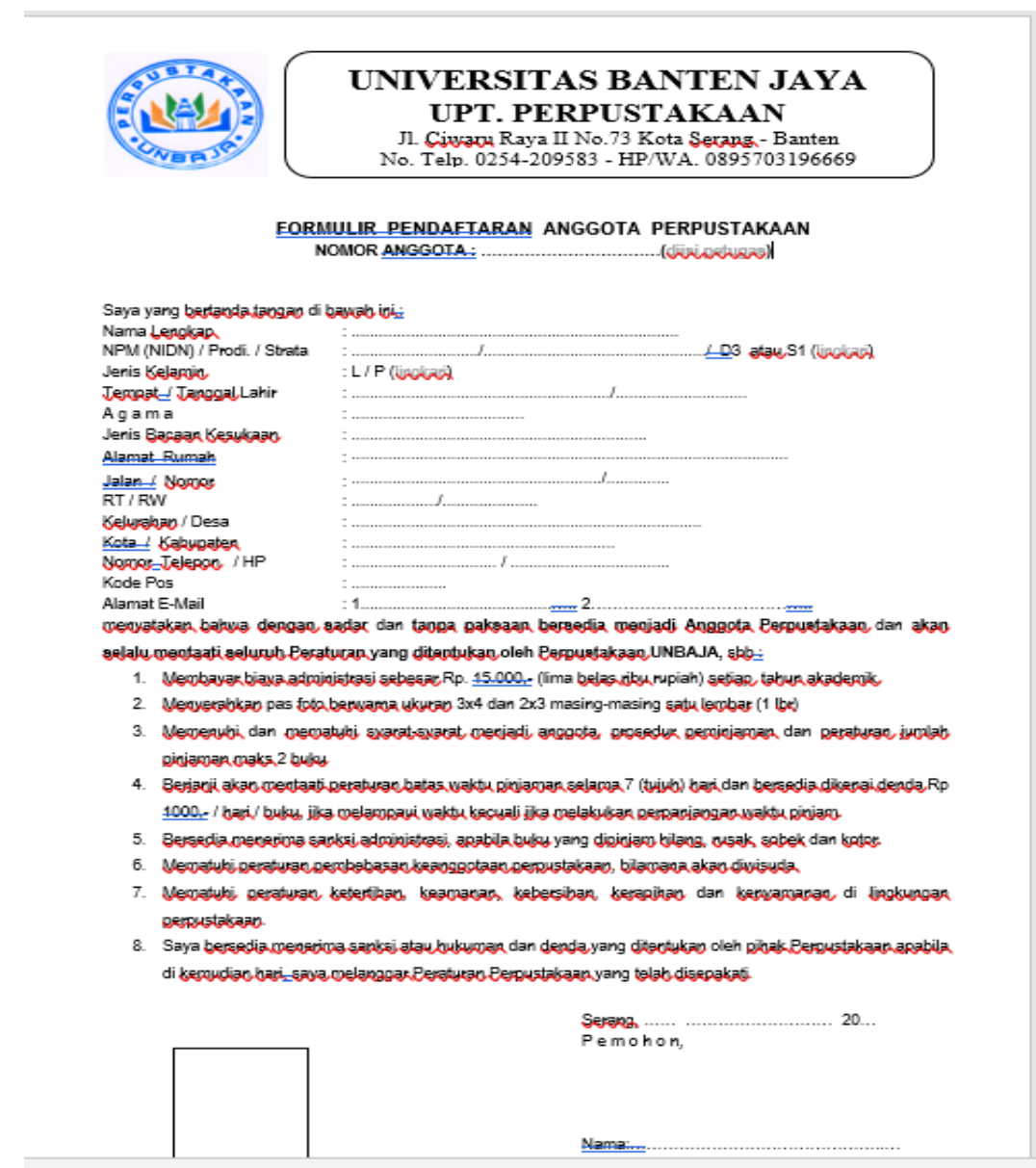

Gambar 3. Formulir Pendaftaran Anggota 
a. Dokumen surat keterangan penyerahan laporan pkn.

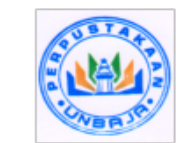

UPT. PERPUSTAKAAN UNIVERSITAS BANTEN JAYA

SURAT KETERANGAN PENYERAHAN LAPORAN PKN

No. 00007 / PKN

\begin{tabular}{|c|c|c|}
\hline Nama & : & Hani Faturrohmah \\
\hline NPM & : & 1102141320 \\
\hline Jur. /Strata & : & $\mathrm{TI} / \mathrm{S}-1$ \\
\hline Fakultas & : & Fakultas IImu Komputer \\
\hline \multicolumn{3}{|c|}{ adalah benar telah menyerahkan Laporan Praktek Kerja Nyata, sbb: } \\
\hline Judul & : & $\begin{array}{l}\text { LAPORAN PRAKTEK KERJA NYATA (PKN) ANALISA SISTEM INFORMASI ABSENSI } \\
\text { PADA PT. LAUTAN OTSUKA CHEMICAL TbK }\end{array}$ \\
\hline Jumlah & : & Satu Eksemplar \\
\hline
\end{tabular}

Serang, 25 September 2020

Ka. UPT. Perpustakaan

$\frac{\text { Rd. Kania, S.Sos., M.Kom }}{\text { NIK. } 7402077010019}$

\section{Gambar 4. Surat Keterangan Laporan PKN}

b. Dokumen surat keterangan penyerahan laporan proposal.

UPT. PERPUSTAKAAN UNIVERSITAS BANTEN JAYA

SURAT KETERANGAN PENYERAHAN PROPOSAL PENELITIAN

No. 00001 / PRPSL

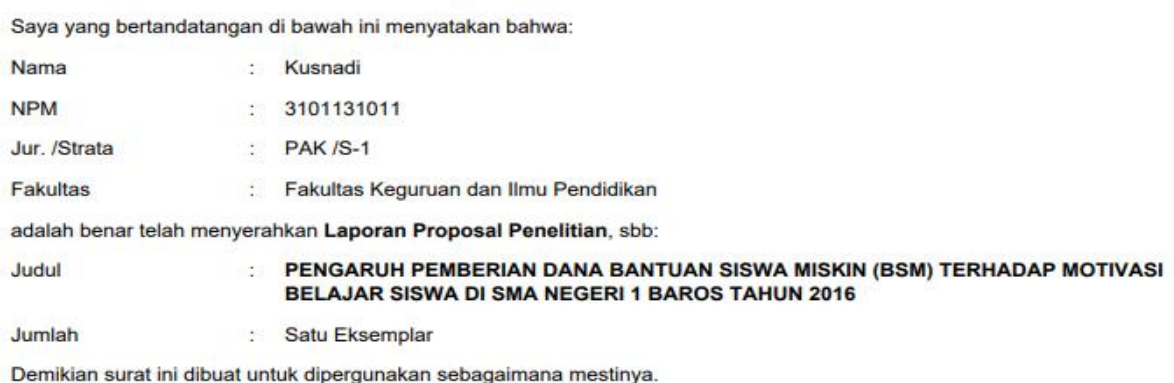

Serang, 25 September 2020 Ka. UPT. Perpustakaan

Gambar 5. Surat Keterangan Laporan Proposal 


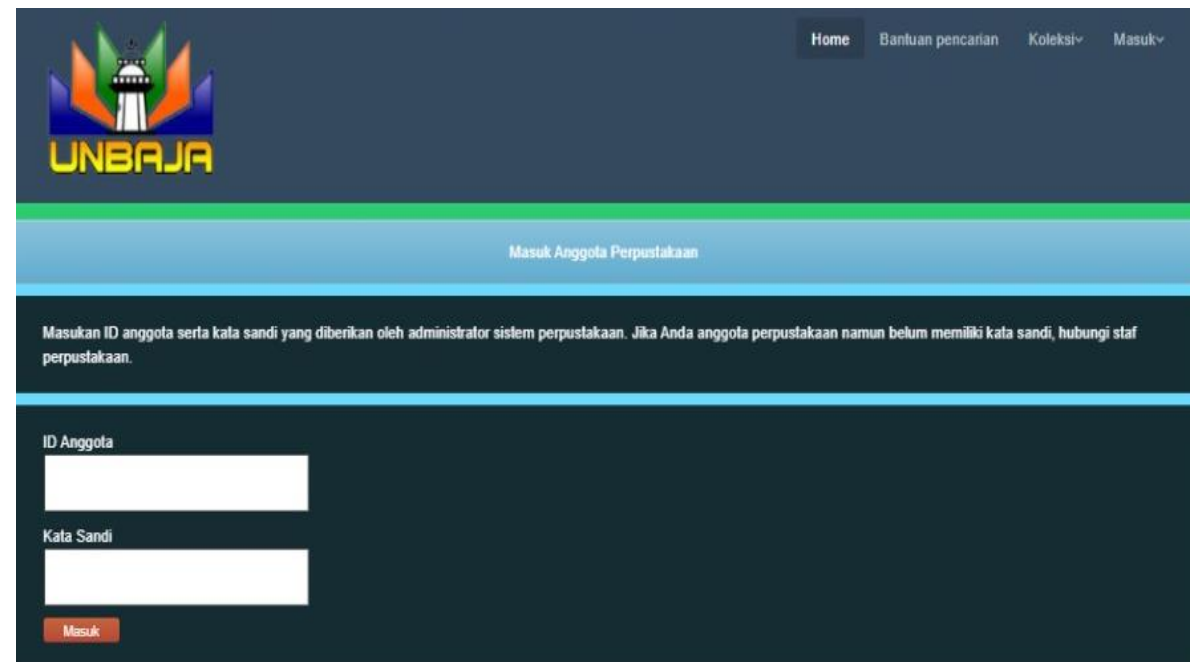

Gambar 8. Tampilan Login Anggota
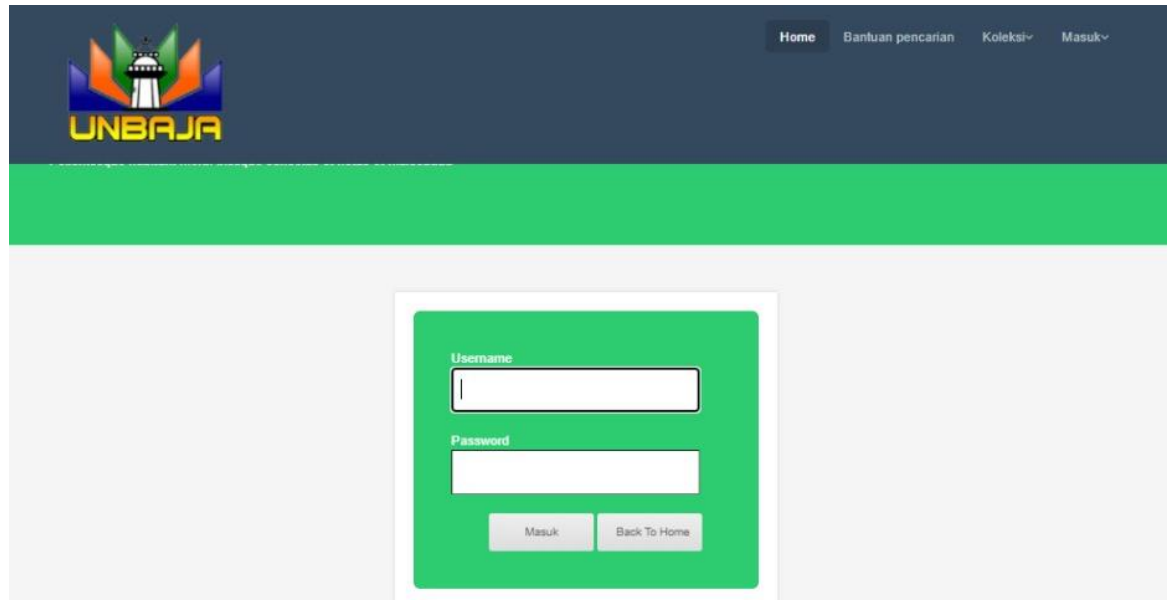

Gambar 9. Tampilan login Admin

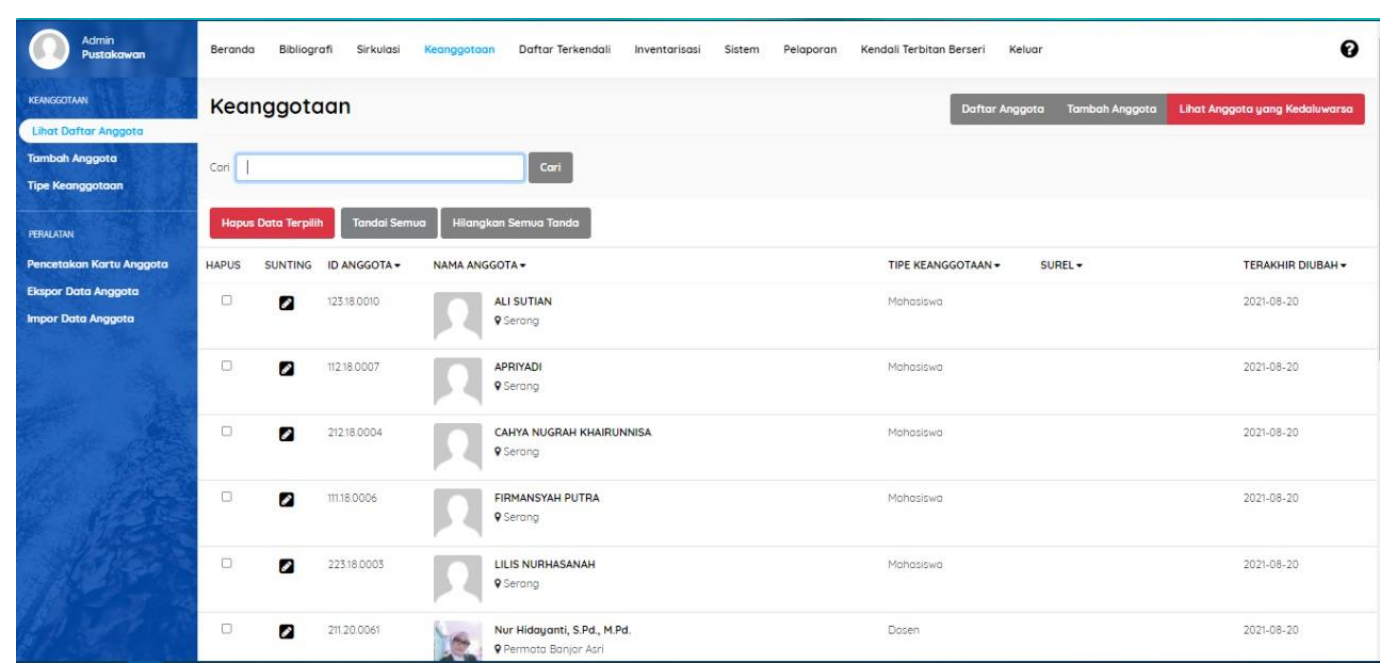

Gambar 10. Tampilan Anggota 


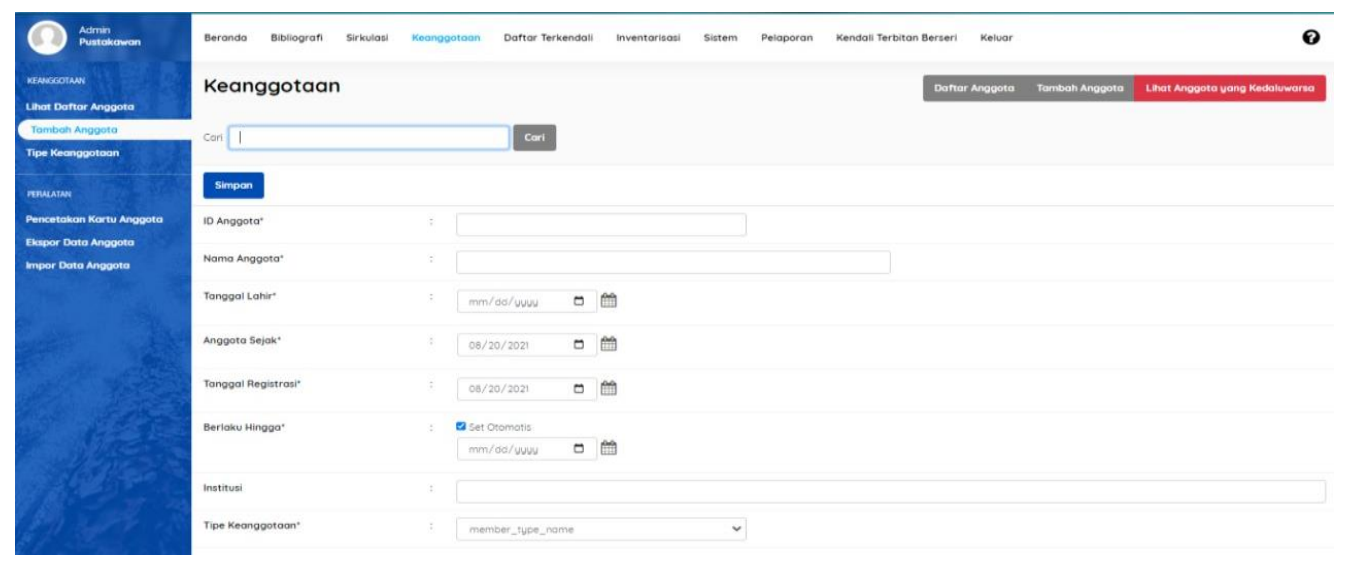

Gambar 11. Tampilan Kelola Data Anggota

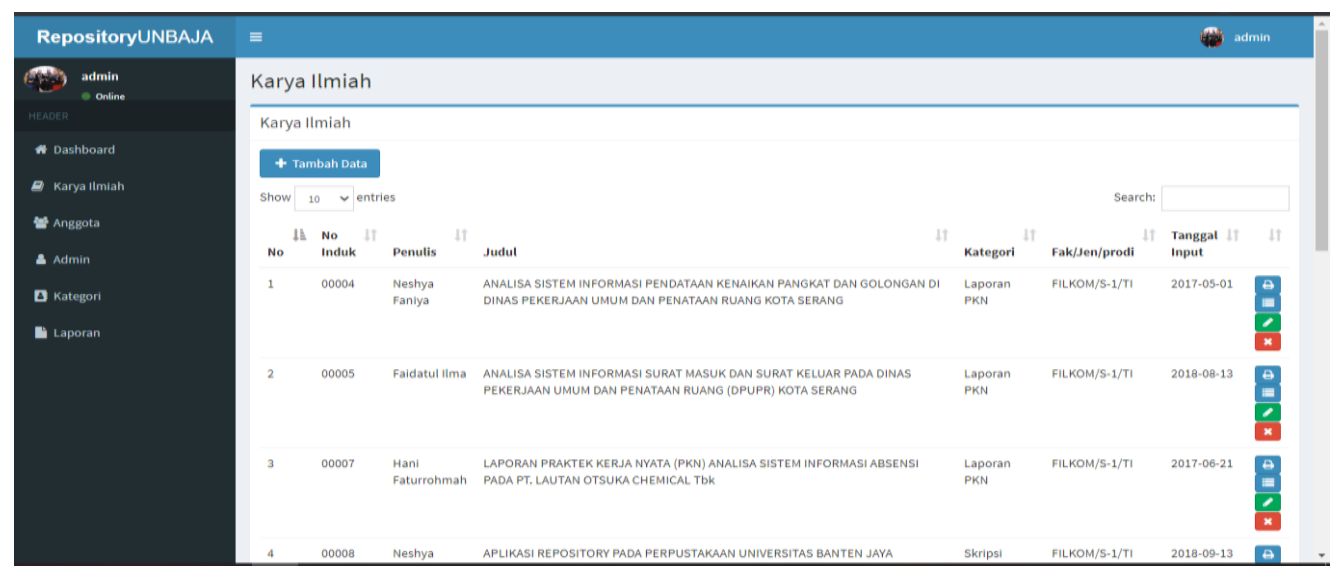

Gambar 12. Tampilan Kelola Data Karya Ilmiah

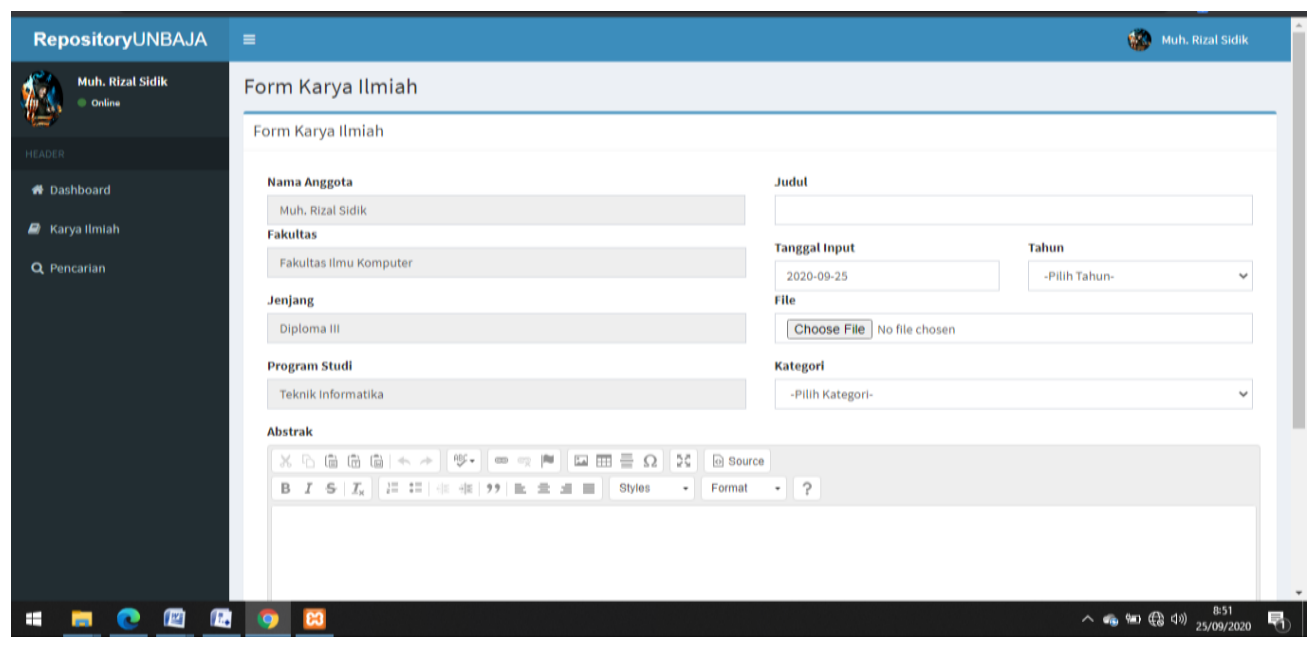

Gambar 13. Tampilan Upload Karya Ilmiah 


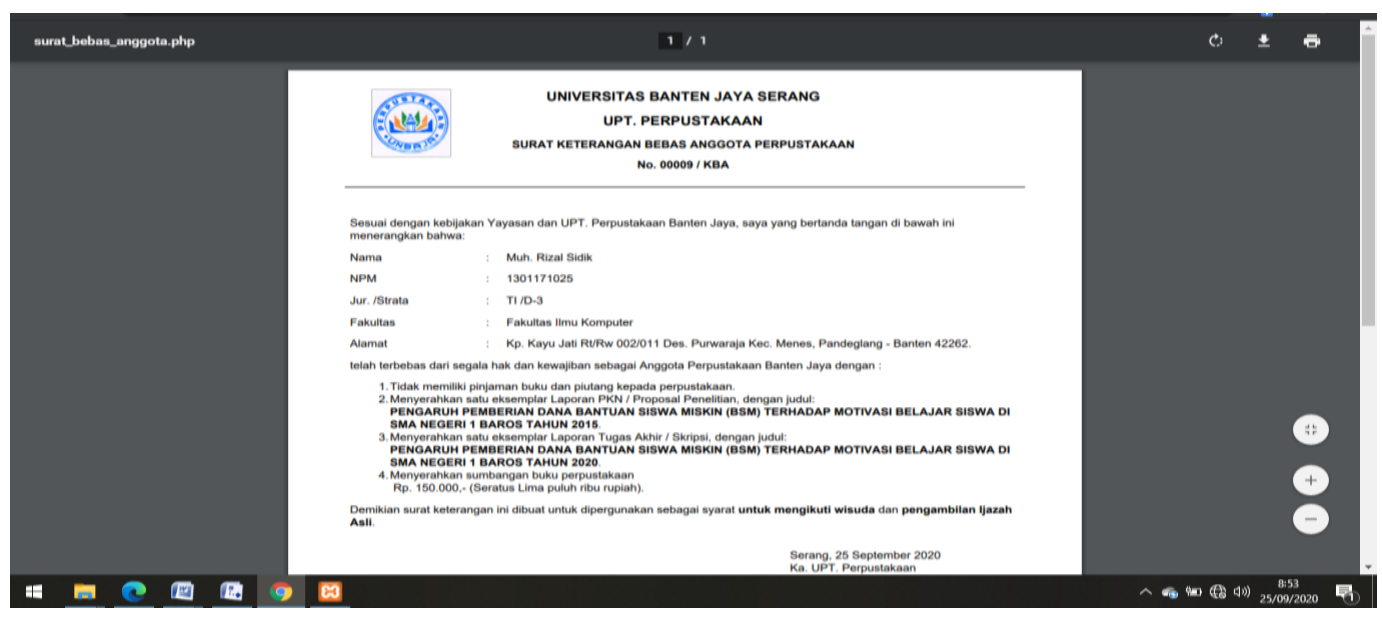

Gambar 14. Tampilan Cetak Bukti Penyerahan Skripsi

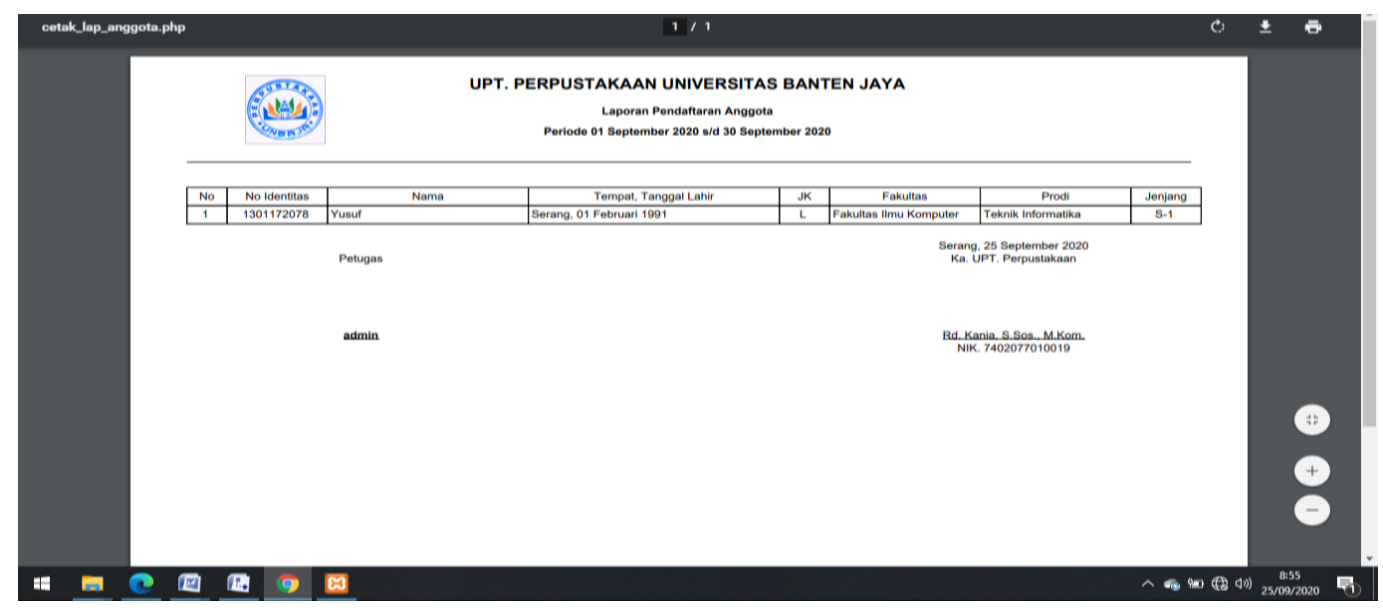

Gambar 15. Tampilan Cetak Laporan Pendaftaran Anggota

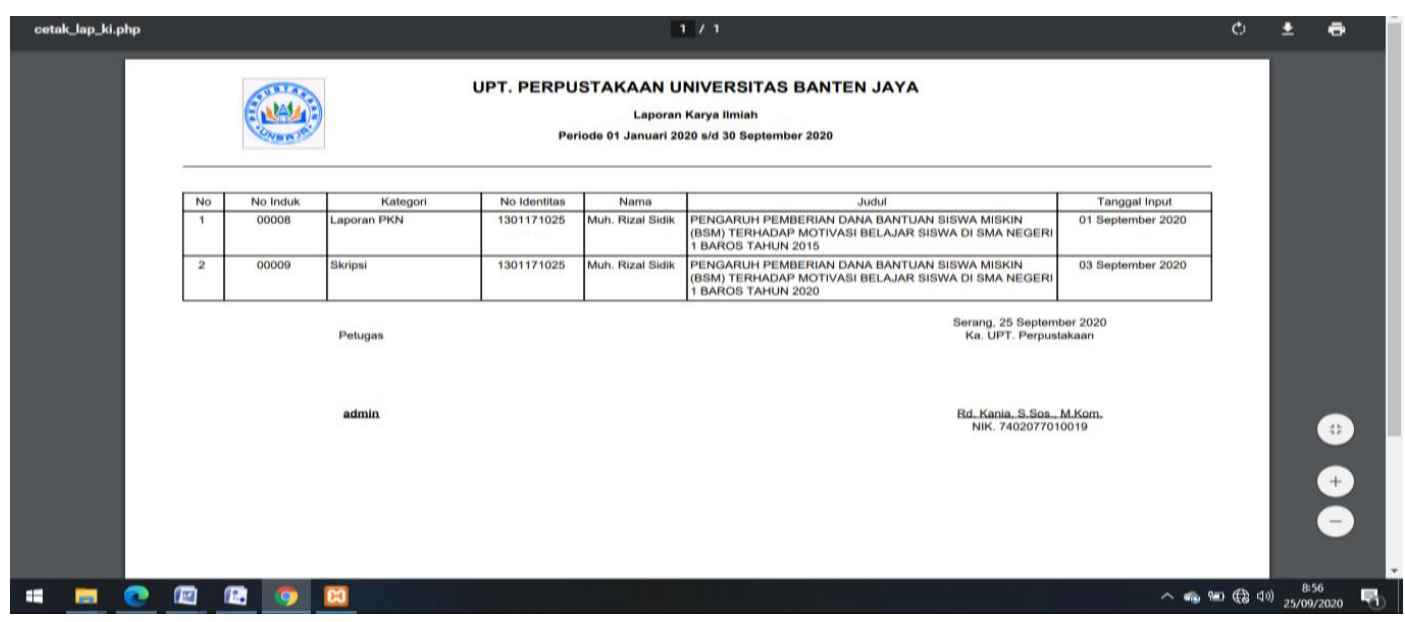

Gambar 16. Tampilan Cetak Laporan Karya Ilmiah 


\section{KESIMPULAN}

Berdasarkan penelitian yang dilakukan oleh penulis memperoleh kesimpulan sebagai berikut :

Sistem ini memudahkan staf dalam pengelolaan karya ilmiah, dimana sistem tersebut dapat dengan mudah dipergunakan mahasiswa dalam mengupload hasil karya ilmiahnya. Selain itu staf dapat dengan mudah mencetak surat penyerahan laporan karya ilmiah tanpa harus membuka file excel yang biasa digunakan untuk mencetak ketika mahasiswa telah melakukan penyerahan skripsi.

Di dalam sistem ini terdapat form cetak laporan yang dapat mempermudahkan staf dalam membuat laporan karya ilmiah, maupun laporan pendaftaran anggota perpustakaan.

Sistem ini sudah terhosting ke internet dengan alamat: http://repositoryunbaja.epizy.com dan juga tersedia form registrasi untuk pendaftaran anggota baru agar mempermudah anggota dalam mengakses dan mengupload hasil karya ilmiahnya ketika sudah terverifikasi oleh pihak admin, serta terdapat form pencarian referensi judul karya ilmiah yang telah tersimpan pada repository perpustakaan Universitas Banten Jaya. Berdasarkan hasil penelitian, maka diperlukan perawatan yang rutin terhadap sistem agar sistem dapat berkembang dan berjalan dengan baik.

\section{DAFTAR PUSTAKA}

Cahyono, N. (2015). Pengertian Perancangan Sistem Informasi. 07/2015.

Hasugian, O. J. (2011). Perpustakaan Digital dan Digital Natives. Perpustakaan Digital Dan Digital Natives, 1-12.

http://repository.usu.ac.id/bitstream/handle/123456789/64595/Lecture Papers.pdf?sequence $=2 \&$ isAllowed $=y$

Kania, K., Nuryani, E., \& Azwarsyah, A. (2019). Rancangan Aplikasi Monitoring Produksi Dan Pengiriman Dengan Metode Shortage Di Pt. Indah Kiat Pulp \& Paper Serang Mill Tbk. Jurnal Sistem Informasi Dan Informatika (Simika), 2(2), 44-51. https://doi.org/10.47080/simika.v2i2.612

Kania, R., Effendy, R., \& Risdiansyah, A. (2021). Sistem Pendukung Keputusan di Pemilihan Karyawan Teladan di universitas Banten Jaya Menggunakan Metode Simple Additive Weighting (SAW). Jurnal Sistem Informasi Dan Informatika (SIMIKA), 4(1), 57-72. http://ejournal.lppmunbaja.ac.id/index.php/jsii/article/view/1186

Kania, R., Hidayanti, N., Nuraida, I., \& Solihati, T. I. (2021). Bakti Kami Pada Pertiwi; Catatan Pengabdian Dosen: Literasi Digital Melalui E-Tourism di Desa Cikolelet Berbasis Kearifan Lokal (F. (Universitas B. J. Oktaviana \& T. A. (Universitas B. J. Mahmud (eds.); 1st ed.). Media Madani Publisher. https://drive.google.com/file/d/1klppCJ6RcM7BnKmJNLZaFU9eR_wAPjlR /view?usp=sharing 
Pendit, P. L. (2013). Digital Native, Literasi Informasi dan Media Digital - sisi pandang kepustakawanan. Seminar Dan Lokakarya Perubahan Paradigma Digital Natives Perpustakaan Universitas - Universitas Kristen Satya Wacana Salatiga 17 - 18 Januari 2013, 1-32. https://www.semanticscholar.org/paper/Digital-Native\%2C-LiterasiInformasi-dan-Media-\%3A-sisiPendit/1ed653f61ce6ce178dee0cb255419d0492a92afc

Perpustakaan Nasional Republik Indonesia. (2015). Pedoman penyelenggaraan perpustakaan perguruan tinggi perpustakaan nasional republik indonesia (1st ed.). Perpustakaan Nasional. https://press.perpusnas.go.id/files/pdf/120.pdf

Reflianto, \& Syamsuar. (2018). Pendidikan dan Tantangan Pembelajaran Berbasis Teknologi Informasi di Era Revolusi Industri 4.0. Jurnal Ilmiah Teknologi Pendidikan, 6(2), 1-13.

Rodliyah, U., \& Habib, H. (2019). Evaluasi Pemanfaatan Institutional Repository (IR) dalam Penyusunan Karya Ilmiah Tugas Akhir Mahasiswa: Studi Kasus PTKIN di Jawa Timur. Indonesian Journal of Academic Librarianship, 3(2), 41-50.

Ruhiawati, I. Y., Gunawan, W., \& Faniya, N. (2020). Aplikasi Repository Pada Perpustakaan Universitas Banten Jaya. Jurnal Sistem Informasi Dan Informatika (Simika), 3(2), 110-126. https://doi.org/10.47080/simika.v3i2.1012

Siregar, A. R. (2013). Pengembangan Repositori Institusi Pengalaman Perpustakaan Usu. Pengalaman Perpustakaan USU - Mei, 1, 1-10. http://repository.usu.ac.id/bitstream/handle/123456789/39523/Pengembanga n Repositori-Pengalaman Perpustakaan USU.pdf;jsessionid=97FF2C7D5EC478F8EA6AA27A4130A7F5?sequence $=1$

Sommerville, I. (2011). Software Engineering. In M. at al Horton, Marcia ; Hirsch (Ed.), Science (Internatio, Vol. 195, Issue 4283). Addison-Wiley. https://doi.org/10.1126/science.195.4283.1199

Sri, Y. (2012). Kajian implementasi tri dharma perguruan tinggi sebagai fenomena pendidikan tinggi di Indonesia. Widya, 29(318), 28-33.

Tarigan, R., \& Ardiansyah, D. (2020). Perancangan Aplikasi Inventory Barang Pada Cv. Mr Lestari Berbasis Web. Jurnal Sistem Informasi Dan Informatika (Simika), 3(2), 77-94. https://doi.org/10.47080/simika.v3i2.985

Tiningsih, E. W. T. (2011). Sistem Informasi Pengolahan Data Perpustakaan pada SMK Negeri 1 Demak. Teknik-Unisfat, 6(2), 89-102.

Untuk, D., Salah, M., Syarat, S., Gelar, M., Ilmu, S., Islam, U., \& Alauddin, N. (2014). Repository Koleksi Karya Ilmiah Di Perpustakaan.

Mulyadi. (2016). Pengertian sistem menurut mulyadi. In Sistem Akuntansi.

Saleh, A. R., \& Komalasari, R. (2014). Pengertian Perpustakaan dan Dasar- Dasar Manajemen Perpustakaan. Manajemen Perpustakaan.

Sora, N. (2014). Mengetahui Pengertian Website Dan Jenisnya. In 07/09. 